\title{
Pathways of Parental Education on Children's and Adolescent's Body Mass Index: The Mediating Roles of Behavioral and Psychological Factors
}

\section{OPEN ACCESS}

Edited by:

Seema Kumar

Mayo Clinic, United States

Reviewed by:

Jared Tucker,

Helen DeVos Children's Hospital,

United States

Ou Yang,

The University of Melbourne, Australia

*Correspondence:

Ann-Katrin Meyrose

a.meyrose@uke.de

tThese authors have contributed equally to this work and share first

authorship

Specialty section: This article was submitted to

Children and Health,

a section of the journa

Frontiers in Public Health

Received: 24 August 2021

Accepted: 31 January 2022

Published: 07 March 2022

Citation:

Seum T, Meyrose A-K, Rabel M,

Schienkiewitz $A$ and

Ravens-Sieberer U (2022) Pathways of Parental Education on Children's

and Adolescent's Body Mass Index:

The Mediating Roles of Behavioral and

Psychological Factors.

Front. Public Health 10:763789.

doi: 10.3389/fpubh.2022.763789

\section{Teresa Seum ${ }^{1 \dagger}$, Ann-Katrin Meyrose ${ }^{1,2 * t}$, Matthias Rabel ${ }^{3}$, Anja Schienkiewitz ${ }^{4}$ and Ulrike Ravens-Sieberer ${ }^{1}$}

\section{${ }^{1}$ Department of Child and Adolescent Psychiatry, Psychotherapy, and Psychosomatics, University Medical Center} Hamburg-Eppendorf, Hamburg, Germany, ${ }^{2}$ Clinical Psychology, Helmut-Schmidt-University/University of the Federal Armed Forces, Hamburg, Germany, ${ }^{3}$ Department of Sport and Health Sciences, Technical University of Munich, Munich, Germany, ${ }^{4}$ Department of Epidemiology and Health Monitoring, Robert Koch-Institute, Berlin, Germany

Aim: The increasing body mass index (BMI) often followed by overweight and obesity is a global health problem of the 21 st century. Children and adolescents with lower socioeconomic status are more affected than their counterparts. The mechanisms behind these differences must be well understood to develop effective prevention strategies. This analysis aims at examining the association of parental education as an indicator of the socioeconomic status on children's and adolescent's body mass index and the role of behavioral and psychological risk factors for a higher BMI longitudinally.

Methods: The analysis was based on a nationwide sample of $N=460$ children and adolescents, aged 11 to 17 at baseline (2009-2012), who took part in the representative BELLA study, the mental health module of the German National Health Interview and Examination Survey among Children and Adolescents (KiGGS). A followup was conducted 5 years later. Using mediation analyses, the mediating effects of breakfast consumption, consumption of sugar-sweetened beverages, screen time, physical activity, mental health problems (Strengths and Difficulties Questionnaire), and health-related quality of life (KIDSCREEN-10) on the association of parent's years of education on their children's BMI were investigated.

Results: A lower level of parental education was significantly associated with a higher $\mathrm{BMI}$ in children and adolescents 5 years later. The association was partially mediated by breakfast consumption and total screen time, with breakfast consumption mediating $16.7 \%$ and total screen time $27.8 \%$ of the association. After controlling for age, gender, and migration status, only breakfast consumption remained a partial mediator (8.5\%). Other included variables had no mediating effects.

Conclusions: Preventive measures should be mainly targeted at children and adolescents of parents with lower educational levels. Tailored strategies to prevent the development of overweight and obesity in this population among children and adolescents should promote daily breakfast consumption at home and reducing screen time.

Keywords: BMI, BELLA study, mediation analysis, longitudinal study, youth, breakfast consumption, screen time 


\section{INTRODUCTION}

The increasing body mass index (BMI) often followed by overweight and obesity is one of the most significant challenges facing public health in the 21st century (1). Worldwide more than 340 million children and adolescents aged 5 to 19 were affected by overweight or obesity in year 2016; thus, $11.4 \%$ of children and adolescents had overweight, and $6.6 \%$ had obesity (2). The current prevalence in Germany is also considerable, with $15.4 \%$ of children and adolescents having overweight and $5.9 \%$ having obesity (3). An increased BMI, overweight and obesity have serious consequences for children and adolescents (1). It can have a significant adverse effect on physical health as well as on social and emotional wellbeing and self-esteem $(4,5)$. Furthermore, childhood obesity is associated with a lower quality of life, poor school performance of children, and elevated risk of teasing, bullying, and social isolation $(1,4)$. Children and adolescents with an increased BMI, are at higher risk of developing overweight and obesity and subsequently, diseases such as cardiovascular disease, hypertension, type 2 diabetes, osteoarthritis, respiratory diseases, and certain cancers (including colorectal cancer, kidney cancer, and esophageal cancer) (68). The negative consequences are usually also observed in adulthood as many children with a high BMI, overweight or obesity maintain their high weight as an adult (9). Long-term effects are premature mortality, a significantly increased risk of later cardiometabolic morbidity, and a significantly increased risk of disability pension $(10,11)$. In addition, childhood obesity also has many economic consequences $(12,13)$. The high prevalence, the complex influencing factors, and the severe consequences make overweight and obesity a significant challenge for the health care system in various areas worldwide.

Overweight and obesity are considered to be the result of a complex interplay of genetic, hormonal and nutritional influences, physical activity as well as social and environmental factors (14). However, overweight and obesity and their related diseases are largely preventable through early and effective prevention (15). Particularly modifiable factors, such as environmental and behavioral factors, are essential in the prevention of overweight and obesity and should, therefore, be given special attention (16). Studies have shown that various factors in prevention, such as limited consumption of sugarsweetened beverages, daily breakfast, reduced screen time, and increased physical activity, are essential in preventing childhood obesity (17-19). Moreover, support for mental health problems and the improvement of quality of life also contribute to preventing overweight $(20,21)$ as well as the consideration of family factors such as socioeconomic status (SES) (22).

Numerous studies suggest that SES affects the risk of developing obesity in both adults and children (23-25). For Germany, the inverse relationship was confirmed by the representative study for children and youth health, KiGGS. The prevalence of overweight was $22.5 \%$ for low SES, $17.4 \%$ for medium SES, and only $12.8 \%$ for high SES (26).

Parental education, as an indicator of SES, has the most consistent inverse association with childhood obesity $(24,27,28)$.
This may partly be due to the fact that parental education has the advantage of being relatively stable; it does not fluctuate according to transient life events as income or occupation can (29). However, the parental educational level does not directly affect the development of overweight or obesity of children, but moreover the behavior and lifestyle factors leading to overweight and obesity (30-32). A higher parental educational level can promote the parents' ability to process health information, which may lead to improved health-related decisions in parenting practice and can also influence the parents' motivation to practice a healthy lifestyle as a role model for their children $(33,34)$. The pathways from SES, measured by the indicators parental education, occupational status, and household income, to health and health-related behaviors were recently analyzed in the KiGGS study $(35,36)$. Results of the study show significant inequalities to the detriment of adolescents from families with low SES in the areas of mental health, physical activity, fresh fruit intake, consumption of sugar-sweetened beverages, and smoking (35, 36). Most of these factors can also be associated with the body mass index of children and adolescents $(20,37-40)$.

To better understand the pathways between parental education, health-related and psychological factors, and body mass index of children and adolescents, mediation analyses are needed. Some cross-sectional studies have already investigated the relationship between parental education, health-related behaviors, and body composition (41-43). The "EuropeaN Energy balance Research to prevent excessive weight Gain among Youth" (ENERGY) project detected that the path between parental education and children's body composition was partially mediated by breakfast consumption, sugar-sweetened beverage consumption, TV viewing, computer use, and sports participation (41). A study by Manios et al. (42) showed that the lower likelihood of having overweight or obesity and higher parental educational status was partially mediated by children's daily breakfast consumption. A study in the Netherlands identified watching TV and consuming breakfast as contributing factors in this association (43). Studies are still lacking that investigate direct and indirect relationships at a longitudinally level as well as studies including psychological factors as mediators (44).

To fill this research gap and therefore better understand the pathways to obesity, develop prevention and intervention programs, and support effective policy-making, this study aimed to investigate the direct and indirect effects of parental education via behavioral and psychological factors on the body mass index of children and adolescents aged 11 to 17 years longitudinally. Single mediation analyses were used to individually assess the effect of parental education via behavioral and psychological factors (breakfast consumption, consumption of sugar-sweetened beverages, total screen time, physical activity, mental health problems and quality of life) on the body mass index. Multiple mediation analyses were carried out to compare the importance of the mediators. Age, gender, and migration status were included in the analyses as covariates. They have shown to be significantly linked to the outcome and the mediators (45). This study used data from the nationally 
representative survey on mental health and behavior of children and adolescents in Germany, the BELLA study (46).

In this study we focused on the following four hypotheses: (1) a lower level of parental education is associated with a higher body mass index in children and adolescents 5 years later; (2) a lower level of parental education is linked to behavioral and psychological risk factors (skipping breakfast, higher consumption of sugar-sweetened beverages, higher amount of total screen time, lower physical activity, higher amount of mental health problems and lower quality of life); (3) more pronounced risk factors cohere with a higher body mass index 5 years later; (4) parental education has an indirect effect (via breakfast consumption, consumption of sugar-sweetened beverages, total screen time, physical activity, mental health problems, quality of life) on the child's and adolescent's body mass index.

\section{MATERIALS AND METHODS \\ Study Design}

The data for the following analyses comes from the prospective, longitudinal BELLA cohort study, the mental health module of the German National Health Interview and Examination Survey for children and adolescents (KiGGS) $(46,47)$. The BELLA cohort study is a representative subsample of KiGGS and examines the mental health and wellbeing of children and adolescents aged 7 to 17 years. Study participants were enrolled in a two-stage random sampling procedure, consisting of a selection of 167 sample points throughout Germany and further sampling of participants from official registers of the residents' registration offices. Data from the baseline assessment (2009-2012) and the follow-up (2014-2017) were used in the analyses for this study. Through computer-assisted telephone interviews and subsequent questionnaires, data was collected for the baseline assessment. For the follow-up, participants were additionally examined by a medical professional. Before being questioned or examined, written informed consent was given by the participants' parents (if aged 7-17) and additionally by the participants themselves (aged 14 or older) for each measurement point.

The BELLA study was approved for both measurement points from the ethics committee of the University Hospital Charitè in Berlin, and the Federal Commissioner for Data Protection in Germany. Design and methods are published elsewhere $(46,48)$.

\section{Participants}

Of 3,840 children and adolescents partaking in the BELLA study baseline assessment, 460 participants were included in the presented analyses. Information about general drop-out and response in the BELLA study can be found in Otto et al. (46). The prerequisites for inclusion in the study were the following: (i) participation at the baseline assessment, (ii) age between 11 and 17 at baseline, (iii) participation at the followup and (iv) participation at the physical examination at the follow-up. Age restriction is caused due to the need for both parent-reported and self-reported data at the baseline assessment. Baseline characteristics of the study sample and children and adolescents of the same age range without follow-up data were compared. The selection of study participants is also presented in Figure 1.

\section{Measurements \\ Outcome Measure: Children's and Adolescent's Body Mass Index}

Standardized measurements of body weight and height were obtained at the physical examination at the follow-up. Participants were measured in underwear by trained assistants. For each of the participants, the body mass index (BMI) was calculated as weight in kilograms divided by height in meters squared. For sensitivity analysis, we utilized BMI percentile ranks to allow comparisons across age and gender, since they are less likely to be outlier prone than raw BMI. The percentile curves based on the German population by Kromeyer-Hauschild et al. (49) were used as the reference population. In addition to data for adolescents, percentiles for adults were included in the analyses to avoid methodological changes in the transition from adolescence to early adulthood (49).

BMI was classified according to international age- and genderspecific International Obesity Task Force (IOTF) standardized BMI cut-off points for participants under the age of 18 (50). The BMI of participants aged 18 and over was categorized using the World Health Organization guidelines (51). According to the guidelines, underweight was defined as a $\mathrm{BMI}<18.5$, normal weight as $18.5 \leq \mathrm{BMI}<25$, overweight as $25 \leq \mathrm{BMI}<30$, and obesity as a BMI $\geq 30$.

\section{Predictor: Parental Education}

Parental education was measured at baseline assessment and reported by the parents. It consists of the sum of years spent on school education and vocational qualification. By using categories of German school-leaving certificates the parent's years spent on school education were estimated (e.g., 13 years for German Abitur; 10 years for German Mittlere Reife; 8 years for people still enrolled in school). In addition, their vocational qualifications were considered (e.g., 5 years for a university degree; 3 years for a completed vocational training; 1.5 years for a completed basic training). To calculate the total score of parental education, the mean of the mother's and father's years spent in school education and vocational qualification was added. The rational for using the average approach of both parents' education follows Thaning and Hällsten (52): Based on their analyses, authors recommend to use the averaged parental education for a simple interpretation prior to the conventional dominance approach or only information for one parent, because both parents are important and increase variation of socioeconomic background.

\section{Potential Mediators}

Six potential mediators were used in the analyses; four behavioral factors, and two psychological factors. Behavioral factors were breakfast consumption, consumption of sugarsweetened beverages, physical activity, and total screen time. Psychological factors were mental health problems and quality of life. All mediators were assessed at the baseline assessment, and all were self-reported. 


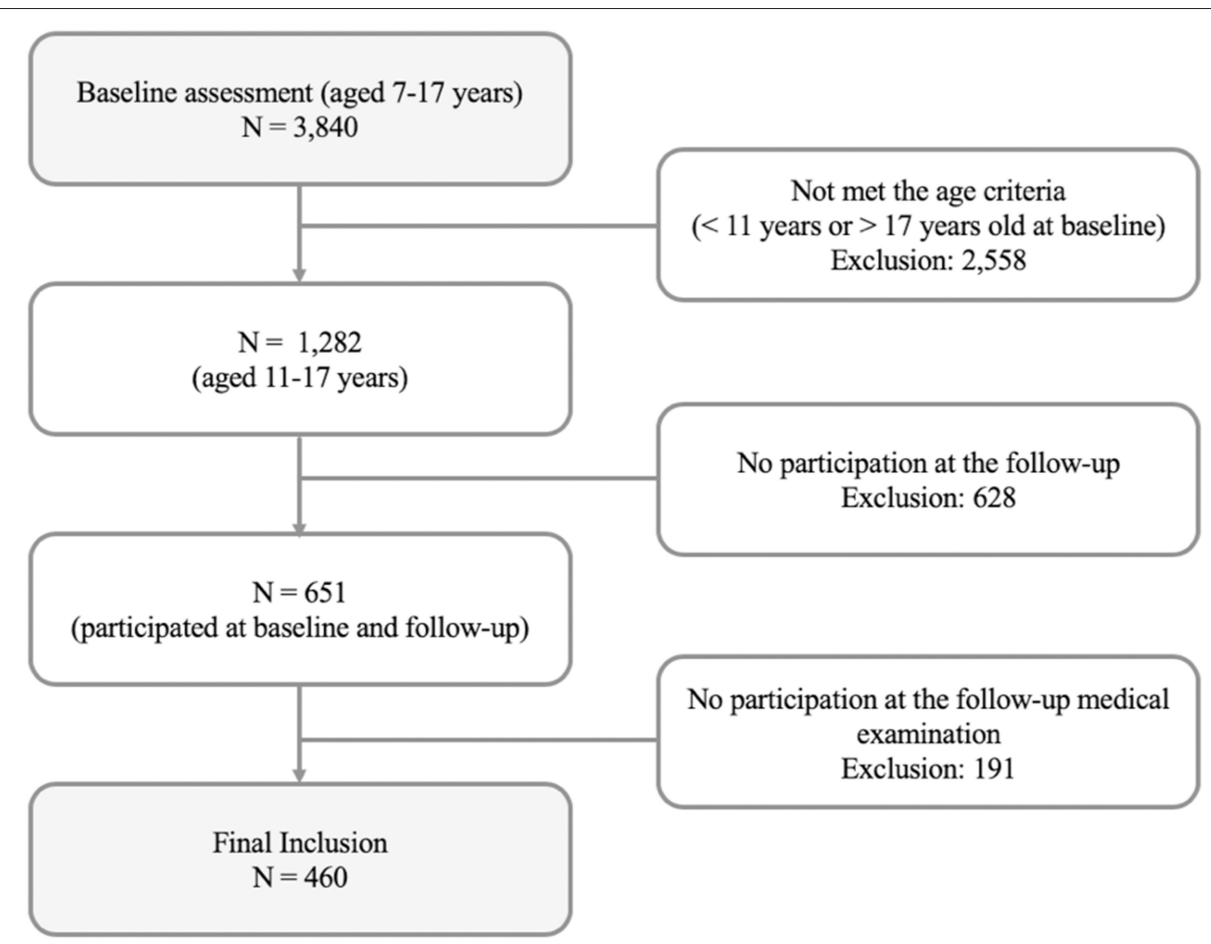

FIGURE 1 | Flow chart for selection of study participants based on the prerequisites for inclusion.

\section{Breakfast Consumption}

To assess the participant's breakfast consumption, they were asked about on how many weekdays they eat breakfast at home. Weekdays were defined as Monday to Friday. Possible responses were scored the following: $5=$ Yes, always, $3.5=$ Yes, 3 to 4 times a week, $1.5=$ Yes, 1 to 2 times a week, $0=$ Never.

\section{Consumption of Sugar-Sweetened Beverages}

To determine the consumption of sugar-sweetened beverages, participants were asked the following questions: "How often do you drink sugar sweetened-beverages?." Four answer possibilities were given: Every day, At least once a week, Less than once a week and Never. Depending on the answer, participants were asked: "How many glasses of sugar sweetened-beverages do you drink per day?” or "per week?.” A glass was defined as $200 \mathrm{ml}$. If the participant indicated a daily consumption in the first question, the portion was converted into the corresponding amount per week. A total score was calculated according to the frequency of consumption per week.

\section{Physical Activity}

Participants were asked as follows to assess physical activity: "On how many days of a normal week are you physically active for at least $60 \mathrm{~min}$ a day?." The eight answer categories ranged from 0 $=$ On no day to $7=7$ days.

\section{Total Screen Time}

To measure the total amount of screen time participants were asked: "How much time do you spend on average per day doing the following? Watching television/video, using a computer/internet, playing video games, using a cell phone." Answer options were scored $0=$ not at all, $1=$ up to $1 \mathrm{~h}, 2=$ up to $2,3=$ up to $3 \mathrm{~h}, 4=$ up to $4 \mathrm{~h}$ and $5=$ more than $4 \mathrm{~h}$. A total screen time score was calculated by adding the hours spent on a daily basis with the respective activities and converting them into the amount per week.

\section{Mental Health Problems}

The Strength and Difficulty Questionnaire (SDQ) was used to assess mental health problems (53). The Total Difficulties Score was calculated by summing 20 items from the four subscales "emotional problems," "conduct problems," "hyperactivity/inattention," and "peer relationship problems." It ranges from 0 to 40 , with higher score indicating more serious mental health problems. The items of the SDQ were scored on a three-point scale $(1=$ not true, $2=$ somewhat true, $3=$ certainly true). The SDQ is a valid and reliable questionnaire which is well-established for the screening of mental health problems in children and adolescents (54).

\section{Health-Related Quality of Life}

Using the KIDSCREEN-10, the health-related quality of life (HRQoL) of the participants was assessed (55). The KIDSCREEN-10 is a brief form of the KIDSCREEN-52 and measures HRQoL from the child's perspective with 10 items. Responses are recorded on a 5-point response scale ranging from never to always, or from not at all to extremely. Items were reversed where necessary to ensure that higher scores indicate 


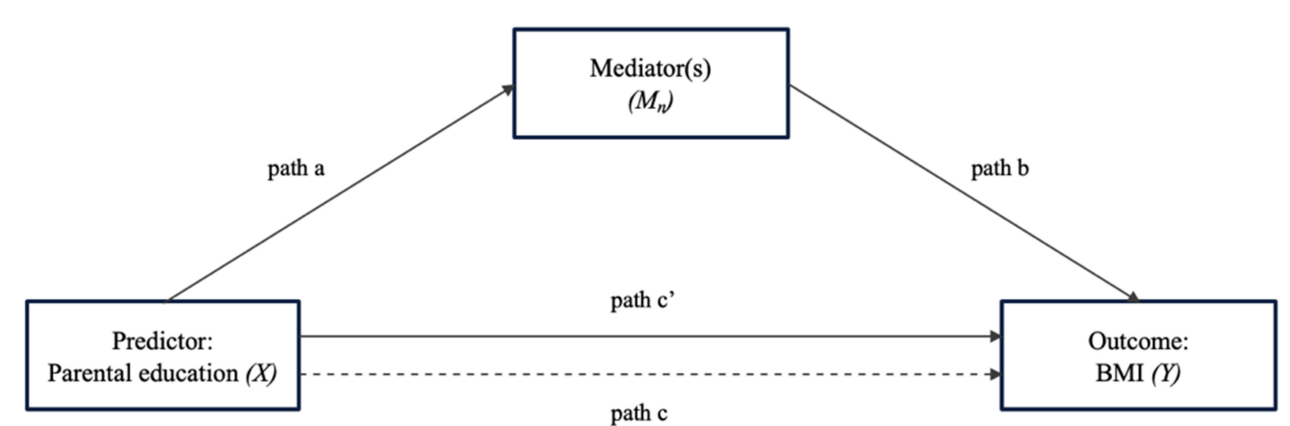

FIGURE 2 | Path diagram for the effect of the predictor variable on the outcome variable through the mediator variable(s). a, effect of $X$ on $M$; b, effect of $M$ on $Y$ controlling for the effect of $X$; $c^{\prime}$, direct effect of $X$ on $Y$; c, total effect of $X$ on $Y$ (sum of the indirect effect and direct effect; i.e., $c=a^{\star} b+c^{\prime}$ ).

a better HRQoL. For each participant, items were summed and were transformed into $T$-values with a mean of 50 and a standard deviation of approximately 10. Previous studies have established that this index has acceptable reliability, with a Cronbach's alpha $>0.80(56,57)$.

\section{Covariates (Age, Gender, Migration Background)}

Covariates were assessed at baseline and included the participant's gender $(0=$ female, $1=$ male $)$, their age (in years) and their migration status $(0=n o, 1=y e s)$. A child or adolescent was defined as having a migration status if they immigrated from another country and at least one parent was not born in Germany, or both parents immigrated and/or had non-German citizenship.

\section{Statistical Analysis}

Descriptive statistical analyses (i.e., frequencies, means, and standard deviations) were done for all analyzed variables. To explore whether breakfast consumption, consumption of sugarsweetened beverages, physical activity, total screen time, mental health problems and HRQoL have an effect on the association between parental education and children's and adolescent's body mass index, mediation analyses were conducted. Mediation occurs when an independent variable $(\mathrm{X})$ influences a dependent variable $(Y)$ through one or more mediator(s) $(\mathrm{M})(58,59)$. The statistical analysis corresponds to the recommendations of Hayes (59). Figure 2 depicts the mediation model followed (PROCESS Macro Model 4).

First, each potential mediator (breakfast consumption, consumption of sugar-sweetened beverages, physical activity, total screen time, mental health problems and HRQoL) was examined separately in mediation analyses through PROCESS macro software on SPSS (60). In a single mediation analysis, path a represents the effect of $\mathrm{X}$ on $\mathrm{M}$, and path $\mathrm{b}$ represents the effect of $\mathrm{M}$ on $\mathrm{Y}$ controlling for the effect of $\mathrm{X}$. The direct effect of $\mathrm{X}$ on $\mathrm{Y}$ is expressed as path $\mathrm{c}^{\prime}$. The indirect effect of $\mathrm{X}$ on $\mathrm{Y}$ through $\mathrm{M}$ is the product of $\mathrm{a}$ and $\mathrm{b}$ (i.e., $\mathrm{a}^{*} \mathrm{~b}$ ). The total effect of $\mathrm{X}$ on $\mathrm{Y}$ is the sum of the indirect effect and direct effect (i.e., $c=a^{*} b+c^{\prime}$ ). Percentage mediated by the identified mediators is calculated by dividing the indirect effect by the total effect.

Afterward, the mediators with a significant indirect effect were included in the multiple mediator analyses. A multi mediator analysis includes two or more mediators simultaneously to compare the effects. Two multiple mediator analyses were conducted, one including the potential mediators (Multiple mediator model 1) and one adjusted for the covariates age, gender, interaction of age $\times$ gender and migration status (Multiple mediator model 2).

According to Baron and Kenny (61), to classify a variable as a mediator, the following conditions had to be met: (1) the predictor shows a significant effect on the mediator, (2) the predictor shows a significant effect on the outcome when the effect of the mediator is not controlled, (3) the mediator has a statistically significant effect on the outcome, and (4) the predictor's effect on the outcome decreases (partial mediation) or is no longer significant (complete mediation).

For the mediation analyses, the predictor parental education and all mediators as well as the covariate age were centered using the grand mean of the sample. For all analyses the effect sizes, $p$ values, and the corresponding 95\% confidence intervals (CI) are reported. The mediated (indirect) effect was formally examined using a non-parametric bootstrapping procedure $(n=5,000$ samples) that estimated the sampling distribution of the indirect effect and the corresponding bias-corrected and accelerated 95\% CI $(58,59)$. Indirect effects were considered significant when the 95\% CI did not include zero.

Prior to mediation model calculations, missing data of the predictor and mediators were replaced using the ExpectationMaximization (EM) algorithm in order to include all cases $(n=$ 460). Missing values were below 5\% for all mediators and the predictor, besides mental health problems (12\%) and HRQoL (8\%). However, missing cases did not show deviations from other cases. To compare results obtained using imputed data and complete data, sensitivity analyses were computed.

The mediation analyses were assessed using Version 3 of PROCESS macro software, which uses a regression-based approach to mediation (60). PROCESS allows in contrast to others direct quantification of the indirect effects. It uses bootstrapping, an alternative method for testing mediation, that does not assume normality of the sampling distribution and yields greater statistical power (62). This is particularly relevant for highly skewed outcome variables, such as BMI.

To conduct all analyses, version 23 of IBM SPSS was used. The significance level was set as $\alpha<0.05$ for all analyses. 
TABLE 1 | Description of the study sample.

\begin{tabular}{|c|c|c|c|}
\hline & \multicolumn{3}{|c|}{$\begin{array}{l}\text { Children and adolescents } \\
\qquad(n=460)\end{array}$} \\
\hline & $n$ & Valid \% & $M(S D)$ \\
\hline \multicolumn{4}{|l|}{ Gender } \\
\hline Male & 218 & 47.4 & \\
\hline Female & 242 & 52.6 & \\
\hline \multicolumn{4}{|l|}{ Age (in years) } \\
\hline T0 (11-17 years) & 460 & & $14.00(1.84)$ \\
\hline T1 (15-23 years) & 460 & & $18.66(1.92)$ \\
\hline \multicolumn{4}{|l|}{ Migration status (T0) } \\
\hline Yes & 30 & 6.5 & \\
\hline No & 430 & 93.5 & \\
\hline Parental education (in years, T0) & 459 & & $13.77(2.34)$ \\
\hline $\mathrm{BMI}\left(\mathrm{kg} / \mathrm{m}^{2}\right)(\mathrm{T} 1)$ & 460 & & $22.61(3.98)$ \\
\hline \multicolumn{4}{|l|}{ BMI-categories } \\
\hline Underweight & 35 & 7.6 & \\
\hline Normal weight & 328 & 71.3 & \\
\hline Overweight & 74 & 16.1 & \\
\hline Obese & 23 & 5.0 & \\
\hline $\begin{array}{l}\text { Breakfast consumption (in days } \\
\text { per weekdays, T0) }\end{array}$ & 451 & & $3.94(1.76)$ \\
\hline $\begin{array}{l}\text { Sugar-sweetened beverages (in } \\
\text { glasses per week, T0) }\end{array}$ & 449 & & $7.24(14.74)$ \\
\hline $\begin{array}{l}\text { Total screen time (in hours per } \\
\text { week, T0) }\end{array}$ & 451 & & $38.71(20.81)$ \\
\hline $\begin{array}{l}\text { Physical activity (in days per } \\
\text { week, T0) }\end{array}$ & 449 & & $3.93(1.78)$ \\
\hline $\begin{array}{l}\text { Mental health problems (SDQ } \\
\text { total score, T0) }\end{array}$ & 405 & & $9.47(4.39)$ \\
\hline HRQoL (KIDSCREEN-10, T0) & 423 & & $52.03(8.72)$ \\
\hline
\end{tabular}

TO, Baseline assessment; T1, Follow-up; SDQ, Strengths and Difficulties Questionnaire (51); KIDSCREEN-10, HRQOL Index (53). M, mean; SD, standard deviation.

\section{RESULTS}

\section{Sample Characteristics}

Table 1 presents descriptive statistics for all variables in the analyses. Longitudinal data of $n=460$ of the children and adolescents $(52.6 \%$ female) were analyzed. At the baseline assessment, participants were between 11 and 17 years old $(M=$ $14.00, S D=1.84)$ and between 15 and 23 years at the follow-up $(M=18.66, S D=1.92)$. Overall, $6.5 \%$ of the participants had a migration status.

The mean BMI measured at the follow-up assessment was 22.61 ( $S D=3.98)$. Of all participants, $7.6 \%$ were categorized as underweight, $71.3 \%$ as normal weight, $16.1 \%$ as overweight, and $5.0 \%$ as obese. The mean years of parental education were 13.77 $(S D=2.34)$, with the lowest being 9.75 years and the highest 18 years.

The comparison of baseline characteristics of the sample used in the analyses and children and adolescents of the same age range without follow-up data revealed a small to medium difference in the averaged age (study sample: $M=14.00$ vs. sample without follow-up data: $M=14.76$ ) and small differences in breakfast consumption and total screen time with healthier behavior in the study sample. No further differences between the samples were detected. Underlying statistics are provided in Supplementary Table 1.

\section{Mediation Analyses \\ Single Mediator Models}

Table 2 presents the results of the single mediation analyses for each potential mediator of the association between parental education and children's and adolescent's BMI. A significant total effect (path c) of parental education on the child's and adolescent's BMI was found. Children of parents with a lower educational level were significantly more likely to have a higher BMI (ß:-0.25; CI:-0.40,-0.09).

There was a significant effect of parental education on several potential mediators (path a). Parental education was positively associated with breakfast consumption ( $($ : 0.08; CI: 0.01 ; 0.15) (i.e., lower parental education, less regular breakfast consumption) and negatively associated with consumption of sugar-sweetened beverages ( $(:-1.38$; CI:-1.94;-0.82), total screen time ( $ß:-2.17$; CI:-2.96;-1.38) and mental health problems ( $(:-0.23$; CI:-0.39;-0.07) (i.e., lower parental education, higher consumption of sugarsweetened beverages, longer total screen time and more mental health problems). There was neither a significant association between parental education and physical activity nor parental education and HRQoL.

Path $b$, the association between a potential mediator and BMI adjusted for parental education, showed two significant effects. Breakfast consumption had a negative ( $(3:-0.36$; CI:-0.56;-0.15) and total screen time a positive effect $(B: 0.03$; CI: $0.01 ; 0.04)$ on the BMI.

Both potential mediators also showed an indirect effect (breakfast consumption: $ß:-0.03$; CI: $-0.07 ;-0.01$; total screen time: $B:-0.06 ; \mathrm{CI}:-0.10 ;-0.02)$. As the direct effect was also significant (breakfast consumption: $B:-0.22$; CI:-0.37; -0.07 ; total screen time: $ß:-0.19 ; \quad C I:-0.35 ;-0.03)$, breakfast consumption and total screen time can separately be identified as partial mediators.

\section{Multiple Mediator Models}

The results concerning the multiple mediation models are presented in Figures 3, 4. The two identified mediators with significant indirect effects in the single mediation model were included in the multiple mediation models.

Results from multiple mediator model 1 (see Figure 3) are comparable to the results of the single mediation models, as both breakfast consumption and total screen time were identified as partial mediators again. Breakfast consumption mediated $16.7 \%$ and total screen time $27.8 \%$ of the association between parental education and BMI.

In multiple mediator model 2 (see Figure 4), the analysis was adjusted for the covariates age, gender, interaction of age $\times$ gender, and migration status. The effect sizes of the previously identified mediators decreased and total screen time showed 
TABLE 2 | Single mediator models.

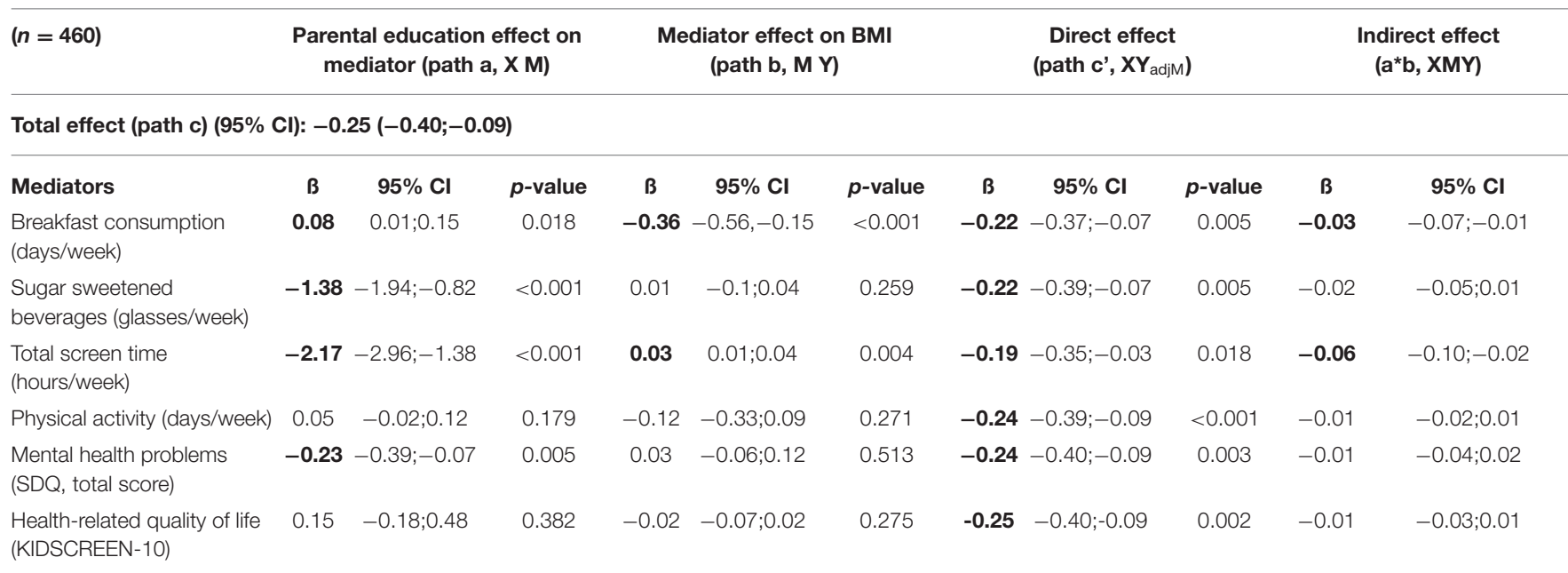

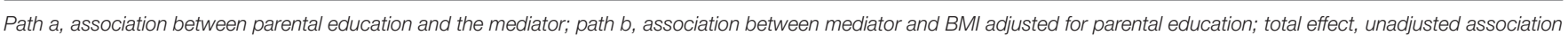

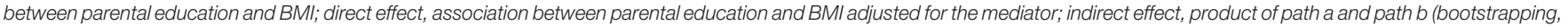
5,000 samples). X, Predictor (Parental education); Y, Outcome (BMI); M, Potential mediator; 3 , unstandardized regression coefficient; significant effects in bold.

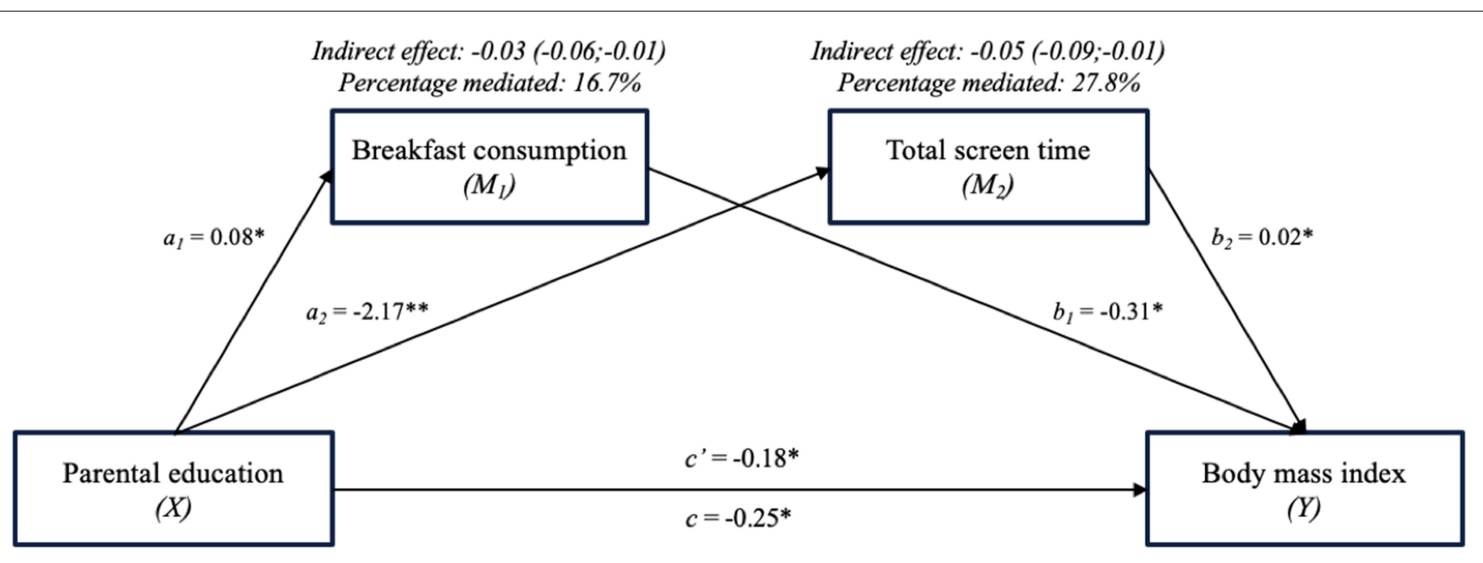

FIGURE 3 | The mediating effect of breakfast consumption and total screen time on the association between parental education and BMI (Multiple mediator model 1). ${ }^{*} p<0.05$.

no significant indirect effect on the association of parental education and BMI anymore. Breakfast consumption mediated $8.5 \%$ after adjusting for the covariates. In Table 3 the effects of the covariates on the multi mediation model are presented. Gender had a significant effect on breakfast consumption (ß:-0.50; CI:-0.80,-0.18), age had a significant effect on total screen time ( $ß: 4.81$; CI: $1.88,7.75)$ and on BMI ( $ß: 1.05$; CI: $0.45,1.66)$. Furthermore, the interaction of age and gender ( $ß:-0.41 ; C I:-0.79,-0.04)$ and the migration status ( $ß:-1.55$; CI:-2.97,-0.13) had significant effects on BMI. In the total effect model age $(ß: 1.12$; CI: $0.52 ; 1.72)$, the interaction of age and gender $(B:-0.42 ; \mathrm{CI}:-0.80,-0.04)$ and migration status (B:-3.16; CI:-3.16,-0.33) had significant effects on BMI.

\section{Sensitivity Analyses}

Sensitivity analyses were performed to compare the results (i) with and without missing data imputation and (ii) using raw BMI scores and BMI percentiles as the outcome. Firstly, no substantive differences between imputed and original data were found (results not presented in detail). Secondly, using BMI percentiles, results of the single mediator models were mostly robust. The total effect from parental education to BMI percentiles (ß:-1.99; CI:-3.15,-0.84), the indirect effect via breakfast consumption ( $ß:-0.15 ; \mathrm{CI}:-0.38,-0.003)$ and the non-significant associations of the other potential mediators (i.e., consumption of sugarsweetened beverages, physical activity, mental health problems, HRQOL) and BMI were confirmed. In contrast, the indirect effect

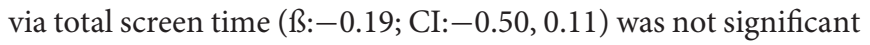
now (results not presented in detail).

\section{DISCUSSION}

In this longitudinal study, the direct and indirect paths of behavioral and psychological factors on the association between 


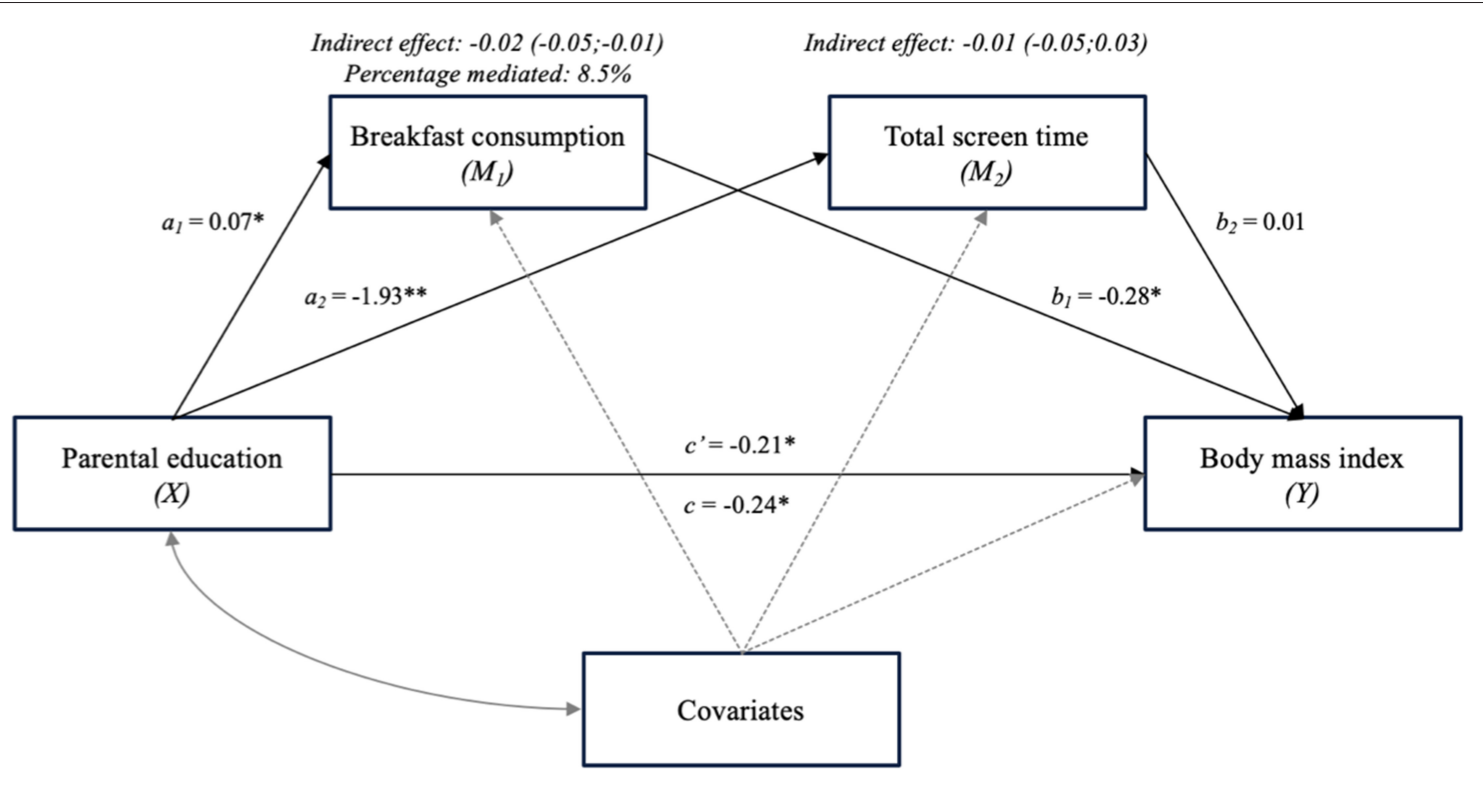

FIGURE 4 | The mediating effect of breakfast consumption and total screen time on the association between parental education and BMI, adjusted for covariates (age, gender, interaction of age $\times$ gender, migration status) (Multiple mediator model 2). ${ }^{*} p<0.05$.

TABLE 3 | Effects of the covariates in the multiple mediator model (Multiple mediator model 2).

\begin{tabular}{|c|c|c|c|c|c|c|c|c|c|c|c|c|}
\hline \multirow{2}{*}{$\begin{array}{l}(n=460) \\
\text { Covariates }\end{array}$} & \multicolumn{3}{|c|}{ Breakfast consumption (M) } & \multicolumn{3}{|c|}{ Total screen time (M) } & \multicolumn{3}{|c|}{$\mathrm{BMI}(\mathrm{Y})$} & \multicolumn{3}{|c|}{ Total effect } \\
\hline & B & $95 \% \mathrm{Cl}$ & $p$-value & B & $95 \% \mathrm{Cl}$ & $p$-value & B & $95 \% \mathrm{Cl}$ & $p$-value & B & $95 \% \mathrm{Cl}$ & $p$-value \\
\hline Age (in years, T0) & -0.15 & $-0.42 ; 0.12$ & 0.276 & 4.81 & $1.88 ; 7.75$ & 0.001 & 1.05 & $0.45 ; 1.66$ & 0.001 & 1.12 & $0.52 ; 1.72$ & $<0.001$ \\
\hline Gender & -0.50 & $-0.80 ;-0.18$ & 0.002 & -0.09 & $-3.39 ; 3.60$ & 0.960 & -0.50 & $-1.05 ; 0.40$ & 0.166 & -0.36 & $-1.06: 0.34$ & 0.316 \\
\hline Interaction age $\times$ gender & 0.02 & $-0.15 ; 0.19$ & 0.827 & -0.46 & $-2.32 ; 1.39$ & 0.622 & -0.41 & $-0.79 ;-0.04$ & 0.032 & -0.42 & $-0.80 ;-0.04$ & 0.030 \\
\hline Migration status (TO) & 0.57 & $-0.06 ; 1.20$ & 0.077 & -6.09 & $-13.0 ; 0.81$ & 0.083 & -1.55 & $-2.97 ;-0.13$ & 0.032 & -1.75 & $-3.16 ;-0.33$ & 0.016 \\
\hline
\end{tabular}

TO, Baseline assessment; X, Predictor (Parental education); Y, Outcome (BMI); M, Potential mediator; C, covariate; B, unstandardized regression coefficient; significant effects in bold.

parental education and the BMI of children and adolescents were examined using data from a large population-based sample from Germany. The results show that the parental education level is inversely associated with the BMI of children and adolescents 5 years later. A lower level of parental education is linked to skipping breakfast, higher consumption of sugar-sweetened beverages, longer total screen time, and a higher amount of mental health problems. Children and adolescents, who skipped breakfast and had a longer total screen time, had a higher BMI 5 years later. Partial mediators of the association between parental education and the BMI were breakfast consumption and total screen time. After adjusting control variables, only breakfast consumption remained significant. The consumption of sugar-sweetened beverages, the duration of physical activity, the amount of mental health problems, and the level of HRQoL had no mediating effect on the association between parental education and BMI.

The first hypothesis, i.e., a lower level of parental education is associated with a higher BMI in children and adolescents 5 years later, was confirmed by this study. Other longitudinal and cross-sectional studies reported similar findings. The systematic review by Shrewsbury and Wardle (28), which compared studies examining socioeconomic status and adiposity in childhood, showed that $75 \%$ of the analyzed studies using parental education as an indicator for socioeconomic status found an inverse relationship between parental education and obesity. Recently, a systematic review of longitudinal studies was published, also confirming the relationship between a low parental educational level and an increased BMI (63). For future research it seems promising to disentangle the separate and interactive effects of maternal and paternal educational level on their children's BMI.

The second hypothesis, i.e., a lower parental educational level is associated with behavioral and psychological risk factors, was only partially substantiated in this study. A lower parental education level predicted skipping breakfast, higher consumption of sugar-sweetened beverages, longer total screen time, and a high amount of mental health problems. The results are in line with previous studies. In several European countries, children of lower educated parents were more likely to skip family breakfast than children of more educated parents (64). 
Furthermore, evidence that children of mothers with a low level of education consume more sugar-sweetened beverages than children of mothers with a high level of education was found by a study among 11-year-old children in Norway (65). An inverse relationship between low parental education and longer screen time was found in a study carried out in Norway (66). A systematic review of socioeconomic inequalities and mental health problems confirmed the association between lower parental education and more mental health problems (67).

However, in our study, parental education did not predict the duration of physical activity or the level of quality of life. Gustafson and Rhodes found indefinite results in their review of the relationship between parental education and physical activity (68). The authors explain the findings by a large number of confounders that can occur when measuring physical activity. This could also explain why parental education did not predict physical activity in the presented study. The association between parental education and HRQoL was also investigated by Rueden et al. (69). However, they used the KIDSCREEN52 questionnaire, which measures nine different dimensions of HRQoL, instead of the KIDSCREEN-10, which measures a total HRQoL index. The results of Rueden's et al. study showed that only one of the nine dimensions, i.e., physical wellbeing, was related to parental education.

The third hypothesis, i.e., more pronounced risk factors cohere with a higher BMI 5 years later, could only be confirmed for breakfast consumption and total screen time. There was no significant longitudinal effect of consumption of sugarsweetened beverages, physical activity, mental health problems, or HRQoL on BMI. The longitudinal association between breakfast consumption and BMI was also found by a review in which $80 \%$ of the longitudinal studies examined showed that regular breakfast consumption was associated with a reduced risk of overweight and obesity in children (70). The positive relationship between total screen time and BMI could also be confirmed by a longitudinal study, conducted in the USA, which found an association between longer screen time and higher BMI (69). Another study states that reducing screen time in adolescence and into adulthood can be a promising strategy for reducing the prevalence of obesity (71).

Existing literature reports mixed results concerning the longitudinal effect of the consumption of sugar-sweetened beverages and overweight or obesity. A meta-analysis investigating the effect of the consumption of sugar-sweetened beverages on weight gain found the association to be close to zero (72). However, other studies found a significant effect on the consumption of sugar-sweetened beverages and increase of BMI $(73,74)$. An explanation for these heterogeneous results could be different types of measurements that were used to determine the number of sugar-sweetened beverages consumed. Furthermore, the use of self-reported data could lead to bias as it can be affected by social desirability, especially for those who are already overweight, or the growing awareness of the harmful effects of sugar-sweetened beverage's consumption. Studies that investigated the longitudinal effect of physical activity and BMI showed inconsistent results. In a longitudinal intervention study in the Czech Republic, physical activity had a vital role in reducing overweight and obesity among children (75). Similar results were found by a systematic review investigating the associations between objectively physical activity and adiposity in children and adolescents (76). However, two other studies showed no significant association between physical activity and BMI $(71,77)$. These mixed results could be due to different ways of measuring physical activity. An epidemiological study by Hestetun, Svendsen, and Oellingrath found mixed evidence on the association between overweight and mental health problems in 12- to 13-year-old Norwegian children (78). Reasons for the indefinite association could be the low number of children with a high amount of mental health problems in this study as well as in our study. Further studies should investigate the association in a sample of children with more pronounced mental health problems. As far as we know, HRQoL has only been investigated as a result of BMI (79-81) and not as a predictor for BMI. Therefore, the results of our study cannot be compared to previous literature. More research is needed for investigating HRQoL as a predictor of overweight and obesity.

The fourth hypothesis, parental education has an indirect effect via breakfast consumption, consumption of sugar-sweetened beverages, total screen time, physical activity, mental health problems and HRQoL on the child and adolescent's BMI, was only validated for two of the risk factors. In line with previous studies, the presented study showed significant indirect effects of breakfast consumption and total screen time on the association of parental education and BMI of children and adolescents. Gebremariam et al. (44) review of mediation effects on the link between socioeconomic status (parental education) and obesity, also showed indirect effects of energy balance-related behaviors such as breakfast consumption, television and computer use. In addition, this review confirms the indeterminate role of physical activity, which could be due to the self-reported measurement of physical activity. As this is the first study on the mediating effects of mental health problems and HRQoL on the association of parental education and BMI, further studies are needed to compare results.

The proportion explained by the mediators in the unadjusted model was moderate, with the direct effect remaining significant after adjustment for the mediators. These results imply that other factors not included in the analyses may play a mediative role in the relationship between parental education and child body composition. Future analyses should compare further mediators, as this may increase knowledge of the complex interplay between parental education and child body composition. In addition to the investigated physical and psychological health behaviors of adolescents, studies have shown parental factors as a pathway between parental education and BMI, such as the parent's BMI, parental psychopathology, their working hours, income along with their own health behaviors (82), and their awareness, resources, and abilities to care for their child's health (83). Further promising pathways seem to be parent-child interaction [i.e., attachment, parenting style, neglect $(82,84)$ ], early childhood factors [i.e., breastfeeding, birth weight (85)] and other determinants, such as child-care attendance (82), and critical life events (86). Genetic predispositions to increased BMI can also act as a pathway, since those with higher educational 
attainment may have a lower genetic risk score for an increased BMI (87).

After adjusting for important control variables as age, gender, and migration status or using age- and gender-specific BMI percentiles in the sensitivity analysis, it is shown that the previously significant mediator, total screen time, no longer shows a significant indirect effect and the effect of breakfast consumption decreases. The different effects of age, gender, and migration status indicate there are different pathways of how these risk factors mediate the association between parental education and BMI. Similar effects caused by gender, age, and migration have already been found in previous studies $(28,88-$ 90). These effects and their specific pathways should be further investigated to be able to develop tailored intervention and prevention strategies.

\section{Strengths and Limitations}

When interpreting the results of this study, the following strengths and limitations must be taken into account. The strengths of the studies include the data of the study, which is a partial sample of the BELLA study. The BELLA study is one of the most important longitudinal studies for assessing mental health problems in a population-based sample of children, adolescents, and young adults in Germany. The strengths of the BELLA study lie in the large sample size and the longitudinal timeline, which makes it possible to examine the participants over time. By measuring weight and height during follow-up physical examination, the BMI was calculated based on measured data. This decreases biases that can be caused by a self-reporting weight and height (91). A further advantage of this study is the multiple included behavioral factors as well as psychological factors, which were measured using internationally comparable methods. To the best of our knowledge, this study is the first to examine both behavioral factors and psychological factors on a longitudinal level.

The present study has the following limitations. First, breakfast consumption, consumption of sugar-sweetened beverages, physical activity, and total screen time were assessed in a retrospective self-report. These data are responsible for memory and may suffer from social desirability, which can lead to a bias in the data. Future studies should measure these variables in more objective ways, such as in a clinical setting, documentation in a diary or on digital devices as well as on a longitudinal level. Furthermore, information on the nutritional content of the food consumption variables could be recorded. Although the BMI is a globally established measurement for determining the body composition and is therefore internationally comparable; nevertheless, the BMI has some disadvantages: (i) The proportions of fat and muscle mass are not taken into account and thus, for example, athletes with low fat and high muscle mass, can have a higher than normal BMI and erroneously being categorized as overweight (92); (ii) Yet, BMI percentiles for adolescents and young adults cannot be compared without caution; (iii) To conclude whether someone is (un)healthy or healthier than another more parameters than height and weight would be necessary, e.g. blood parameters (glucose, lipids) or muscle percentage. Finally, there might be unobserved heterogeneity which drive both children's BMI and parental education for what reason causality of effects cannot be claimed. Future studies should measure children's BMI at least twice.

\section{Implications}

Based on previous research, the prevention of overweight and obesity among children and adolescents from families with a higher educational level is more likely to succeed (93-95). However, the results of this study show that children from parents with lower education are more affected by a higher BMI, which can lead to overweight and obesity. Therefore, when developing strategies to reduce the increase of the BMI in children and adolescents, particular attention should be paid to target groups with lower parental educational levels in order to improve effectiveness. Prevention should include measures that reach and are accepted by these groups in particular in addition to scientifically proven ways for prevention of overweight and obesity in general, independently of parental education level. The aim is to support parents and children in changing their breakfast habits toward a regular breakfast every school day and to promote reduced total screen time through improved awareness and information as the results of this study show these factors to be mediating the association between parental education and BMI. To achieve this, measures must be taken at different levels; at the individual level, involving children and their parents, at the school level and with the involvement of politics and society.

\section{CONCLUSION}

This study shows that prevention measures should be particularly targeted at children and adolescents of parents with low levels of education to address the significant public health challenge of increased BMI. Tailored strategies to prevent the development of overweight and obesity in the lower educated population among children and adolescents should develop specific messages focusing on the importance of promoting daily breakfast consumption at home and reducing screen time. Further studies are needed to investigate tailored development, implementation, and evaluation of prevention measures.

\section{DATA AVAILABILITY STATEMENT}

The original contributions presented in the study are included in the article/Supplementary Materials, further inquiries can be directed to the corresponding author/s.

\section{ETHICS STATEMENT}

The studies involving human participants were reviewed and approved by the Ethics Committee of the University Hospital Charitè in Berlin, Germany, and the Federal Commissioner for Data Protection in Germany. Written informed consent to participate in this study was provided by the participants' legal guardian/next of kin. Written informed consent was given by the participants' parents (if aged 7-17) and additionally by the participants themselves (aged 14 or older). 


\section{AUTHOR CONTRIBUTIONS}

TS, A-KM, MR, AS, and UR-S contributed to the conception and design of the study. TS and A-KM organized the database. TS performed the statistical analysis in close consultation with A$\mathrm{KM}$ and MR. AS provided special expertise concerning BMI and overweight. TS wrote the first draft of the manuscript. A-KM wrote sections of the manuscript. UR-S provided resources and conducted project administration and supervision. All authors contributed to manuscript revision, read, and approved the submitted version.

\section{FUNDING}

The German Federal Ministry of Health (BMG) funded the BELLA assessment from 2009 to 2012.

\section{REFERENCES}

1. Lobstein T, Baur L, Uauy R. Obesity in children and young people: a crisis in public health. Obes Rev. (2004) 5:4-85. doi: 10.1111/j.1467-789X.2004.00133.x

2. Abarca-Gómez L, Abdeen ZA, Hamid ZA, Abu-Rmeileh NM, Acosta-Cazares B, Acuin C, et al. Worldwide trends in body-mass index, underweight, overweight, and obesity from 1975 to 2016: a pooled analysis of 2416 population-based measurement studies in 128.9 million children, adolescents, and adults. Lancet. (2017) 390:2627-42. doi: 10.1016/S0140-6736(17)32129-3

3. Schienkiewitz A, Brettschneider A-K, Damerow S, Rosario AS. Übergewicht und Adipositas im Kindes- und Jugendalter in Deutschland - querschnittergebnisse aus KiGGS Welle 2 und trends [overweight and obesity among children and adolescents in Germany - results of the crosssectional KiGGS Wave 2 study and trends]. J Health Monitor. (2018) 3:16-23. doi: 10.1055/s-0038-1667742

4. Sahoo K, Sahoo B, Choudhury AK, Sofi NY, Kumar R, Bhadoria AS. Childhood obesity: causes and consequences. J Family Med Prim Care. (2015) 4:187-92. doi: 10.4103/2249-4863.154628

5. Nieman P, LeBlanc C, Canadian paediatric society, healthy active living and sports medicine committee. Psychosocial aspects of child and adolescent obesity. Paediatr Child Health. (2012) 17:205-6. doi: 10.1093/pch/17.4.205

6. Pi-Sunyer X. The medical risks of obesity. Postgrad Med. (2009) 121:2133. doi: 10.3810/pgm.2009.11.2074

7. Marmot M, Atinmo T, Byers T, Chen J, Hirohata T, Jackson A, et al. Food, Nutrition, Physical Activity, And The Prevention Of Cancer: A Global Perspective. Washington, DC: World Cancer Research Fund / American Institute for Cancer Research (2007).

8. Ezzati M, Lopez AD, Rodgers AA, Murray CJ. Comparative Quantification of Health Risks: Global and Regional Burden of Disease Attributable To Selected Major Risk Factors. Geneva: World Health Organization (2004).

9. Singh AS, Mulder C, Twisk JWR, Mechelen WV, Chinapaw MJM. Tracking of childhood overweight into adulthood: a systematic review of the literature. Obes Rev. (2008) 9:474-88. doi: 10.1111/j.1467-789X.2008.00475.x

10. Reilly JJ, Kelly J. Long-term impact of overweight and obesity in childhood and adolescence on morbidity and premature mortality in adulthood: systematic review. Int J Obes. (2011) 35:891-8. doi: 10.1038/ijo.20 10.222

11. Simmonds M, Llewellyn A, Owen CG, Woolacott N. Predicting adult obesity from childhood obesity: a systematic review and meta-analysis. Obes Rev. (2016) 17:95-107. doi: 10.1111/obr.12334

12. Wenig CM. The impact of BMI on direct costs in Children and Adolescents: empirical findings for the German Healthcare System based on the KiGGSstudy. Eur J Health Econ. (2012) 13:39-50. doi: 10.1007/s10198-0100278-7

13. OECD. The Heavy Burden of Obesity: The Economics of Prevention. Paris: OECD Publishing (2019).

\section{ACKNOWLEDGMENTS}

The authors thank all children, adolescents, their parents and young adults who participated in the BELLA study. We are very grateful to all colleagues who supported our project, especially to PD Dr. Christiane Otto, Dr. Claus Barkmann, Dr. Franziska Reiß, Dr. Anne Kaman and the BELLA study group. Further, we would like to thank the Robert KochInstitute and the Charité Berlin for their ongoing support and cooperation.

\section{SUPPLEMENTARY MATERIAL}

The Supplementary Material for this article can be found online at: https://www.frontiersin.org/articles/10.3389/fpubh. 2022.763789/full\#supplementary-material

14. Gurnani M, Birken C, Hamilton J. Childhood obesity: causes, consequences, and management. Pediatr Clin North Am. (2015) 62:821-40. doi: 10.1016/j.pcl.2015.04.001

15. Hruby A, Hu FB. The epidemiology of obesity: a big picture. Pharmacoeconomics. (2015) 33:673-89. doi: 10.1007/s40273-014-0243-x

16. Davis MM, Gance-Cleveland B, Hassink S, Johnson R, Paradis G, Resnicow K. Recommendations for prevention of childhood obesity. Pediatrics. (2007) 120:S229-53. doi: 10.1542/peds.2007-2329E

17. Pandita A, Sharma D, Pandita D, Pawar S, Tariq M, Kaul A. Childhood obesity: prevention is better than cure. Diabetes Metab Syndr Obe. (2016) 9:83-9. doi: 10.2147/DMSO.S90783

18. Romieu I, Dossus L, Barquera S, Blottière HM, Franks PW, Gunter M, et al. Energy balance and obesity: what are the main drivers? Cancer Causes Control. (2017) 28:247-58. doi: 10.1007/s10552-017-0869-Z

19. Güngör NK. Overweight and obesity in children and adolescents. J Clin Res Pediatr Endocrinol. (2014) 6:129-43. doi: 10.4274/jcrpe.1471

20. Russell-Mayhew S, McVey G, Bardick A, Ireland A. Mental health, wellness, and childhood overweight/obesity. J Obes. (2012) 2012:e281801. doi: 10.1155/2012/281801

21. Hunsberger M, Lehtinen-Jacks S, Mehlig K, Gwozdz W, Russo P, Michels N, et al. Bidirectional associations between psychosocial well-being and body mass index in European children: longitudinal findings from the IDEFICS study. BMC Public Health. (2016) 16:949. doi: 10.1186/s12889-016-3626-4

22. Singh GK, Siahpush M, Kogan MD. Neighborhood socioeconomic conditions, built environments, and childhood obesity. Health Aff. (2010) 29:503-12. doi: 10.1377/hlthaff.2009.0730

23. Chung A, Backholer K, Wong E, Palermo C, Keating C, Peeters A. Trends in child and adolescent obesity prevalence in economically advanced countries according to socioeconomic position: a systematic review. Obes Rev. (2016) 17:276-95. doi: 10.1111/obr.12360

24. McLaren L. Socioeconomic status and obesity. Epidemiol Rev. (2007) 29:29_ 48. doi: 10.1093/epirev/mxm001

25. Barriuso L, Miqueleiz E, Albaladejo R, Villanueva R, Santos JM, Regidor E. Socioeconomic position and childhood-adolescent weight status in rich countries: a systematic review, 1990-2013. BMC Pediatr. (2015) 15:129. doi: 10.1186/s12887-015-0443-3

26. Lampert T, Hagen C, Heizmann B. Gesundheitliche Ungleichheit bei Kindern und Jugendlichen in Deutschland [Health inequalities in children and adolescents in Germany]. Berlin: Robert Koch-Institute (2010).

27. Bammann K, Gwozdz W, Lanfer A, Barba G, Henauw SD, Eiben $\mathrm{G}$, et al. Socioeconomic factors and childhood overweight in Europe: results from the multi-centre IDEFICS study. Pediatr Obes. (2013) 8:112. doi: 10.1111/j.2047-6310.2012.00075.x

28. Shrewsbury V, Wardle J. Socioeconomic status and adiposity in childhood: a systematic review of cross-sectional studies 1990-2005. Obesity. (2008) 16:275-84. doi: 10.1038/oby. 2007.35 
29. Johnson F, Pratt M, Wardle J editors. Socio-economic status and obesity in childhood. In: Epidemiology of Obesity In Children And Adolescents: Prevalence And Etiology. New York, NY: Springer New York (2011). p. 377-90. doi: 10.1007/978-1-4419-6039-9_21

30. Gatineau M, Dent M. Obesity and Mental Health. Oxford: National Obesity Observatory (2011).

31. Lord S, Manlhiot C, Tyrrell PN, Dobbin S, Gibson D, Chahal N, et al. Lower socioeconomic status, adiposity and negative health behaviours in youth: a cross-sectional observational study. BMJ Open. (2015) 5:e008291. doi: 10.1136/bmjopen-2015-008291

32. Rajmil L, Herdman M, Ravens-Sieberer U, Erhart M, Alonso J, The European KIDSCREEN group. Socioeconomic inequalities in mental health and health-related quality of life (HRQOL) in children and adolescents from 11 European countries. Int J Public Health. (2014) 59:95105. doi: 10.1007/s00038-013-0479-9

33. Cutler DM, Lleras-Muney A. Education and Health: Evaluating Theories And Evidence. National bureau of economic research Cambridge, Mass, USA (2006). doi: 10.3386/w12352

34. Wolfson JA, Gollust SE, Niederdeppe J, Barry CL. The role of parents in public views of strategies to address childhood obesity in the United States. Milbank Q. (2015) 93:73-111. doi: 10.1111/1468-0009.12106

35. Lampert T, Hoebel J, Kuntz B, Finger JD, Hölling H, Lange M, et al. Health inequalities among children and adolescents in Germany. Developments over time and trends from the KiGGS study. J Health Monit. (2019) 4:1640. doi: $10.25646 / 5867$

36. Kuntz B, Waldhauer J, Zeiher J, Finger JD, Lampert T. Socioeconomic differences in the health behaviour of children and adolescents in Germany. Results of the cross-sectional KiGGS Wave 2 study. J Health Monit. (2018) 3:44-60. doi: 10.25646/5609

37. Katzmarzyk PT, Barreira TV, Broyles ST, Champagne CM, Chaput J-P, Fogelholm M, et al. Physical activity, sedentary time, and obesity in an international sample of children. Med Sci Sports Exerc. (2015) 47:206269. doi: 10.1249/MSS.0000000000000649

38. Chung AE, Skinner AC, Steiner MJ, Perrin EM. Physical activity and BMI in a nationally representative sample of children and adolescents. Clin Pediatr. (2012) 51:122-9. doi: 10.1177/0009922811417 291

39. Epstein LH, Gordy CC, Raynor HA, Beddome M, Kilanowski CK, Paluch $\mathrm{R}$. Increasing fruit and vegetable intake and decreasing fat and sugar intake in families at risk for childhood obesity. Obes Res. (2001) 9:1718. doi: 10.1038/oby.2001.18

40. Alinia S, Hels O, Tetens I. The potential association between fruit intake and body weight - a review. Obes Rev. (2009) 10:639-47. doi: 10.1111/j.1467-789X.2009.00582.x

41. Fernández-Alvira JM, te Velde SJ, De Bourdeaudhuij I, Bere E, Manios Y, Kovacs E, et al. Parental education associations with children's body composition: mediation effects of energy balance-related behaviors within the ENERGY-project. Int J Behav Nutr Phys Act. (2013) 10:80. doi: 10.1186/1479-5868-10-80

42. Manios Y, Moschonis G, Androutsos O, Filippou C, Van Lippevelde W, Vik FN, et al. Family sociodemographic characteristics as correlates of children's breakfast habits and weight status in eight European countries. the ENERGY (EuropeaN energy balance research to prevent excessive weight gain among youth) project. Public Health Nutr. (2015) 18:77483. doi: 10.1017/S1368980014001219

43. Veldhuis L, Vogel I, Van Rossem L, Renders CM, HiraSing RA, Mackenbach JP, et al. Influence of maternal and child lifestyle-related characteristics on the socioeconomic inequality in overweight and obesity among 5-year-old children; the "be active, eat right" study. Int J Environ Res Public Health. (2013) 10:2336-47. doi: 10.3390/ijerph10062336

44. Gebremariam MK, Lien N, Nianogo RA, Arah OA. Mediators of socioeconomic differences in adiposity among youth: a systematic review. Obes Rev. (2017) 18:880-98. doi: 10.1111/obr.12547

45. Inchley JC, Currie DB, Young T, Samdal O, Torsheim T, Augustson L, et al. Growing Up Unequal: Gender And Socioeconomic Differences In Young People's Health And Well-Being: Health Behaviour In School-Aged Children (HBSC) Study: International Report From The 2013/2014 Survey. Copenhagen: WHO Regional Office for Europe (2016).
46. Otto C, Reiss F, Voss C, Wüstner A, Meyrose A-K, Hölling H, et al. Mental health and well-being from childhood to adulthood: design, methods and results of the 11-year follow-up of the BELLA study. Eur Child Adolesc Psychiatry. (2021) 30:1559-77. doi: 10.1007/s00787-020-01630-4

47. Ravens-Sieberer U, Kurth B-M, the KiGGS study group, BELLA study group. The mental health module (BELLA study) within the German health interview and examination survey of children and adolescents (KiGGS): study design and methods. Eur Child Adolesc Psychiatry. (2008) 17:1021. doi: 10.1007/s00787-008-1002-3

48. Ravens-Sieberer U, Otto C, Kriston L, Rothenberger A, Döpfner M, HerpertzDahlmann B, et al. The longitudinal BELLA study: design, methods and first results on the course of mental health problems. Eur Child Adolesc Psychiatry. (2015) 24:651-63. doi: 10.1007/s00787-014-0638-4

49. Kromeyer-Hauschild K, Moss A, Wabitsch M. Referenzwerte für den Body-Mass-Index für Kinder, Jugendliche und Erwachsene in Deutschland [Body mass index reference values for German children, adolescents and adults]. Adipositas-Ursachen, Folgeerkrankungen, Therapie. (2015) 9:1237. doi: 10.1055/s-0037-1618928

50. Cole TJ, Lobstein T. Extended international (IOTF) body mass index cutoffs for thinness, overweight and obesity. Pediatr Obes. (2012) 7:28494. doi: 10.1111/j.2047-6310.2012.00064.x

51. World Health Organization. Physical status: The Use of and Interpretation of Anthropometry, Report of a WHO Expert Committee. Geneva: World Health Organization (1995).

52. Thaning M, Hällsten M. The end of dominance? evaluating measures of socio-economic background in stratification research. Eur Sociol Rev. (2020) 36:533-47. doi: 10.1093/esr/jcaa009

53. Goodman R. The strengths and difficulties questionnaire: a research note. J Child Psychol Psychiatry. (1997) 38:58186. doi: 10.1111/j.1469-7610.1997.tb01545.x

54. Goodman R. Psychometric properties of the strengths and difficulties questionnaire. J Am Acad Child Adolesc Psychiatry. (2001) 40:133745. doi: 10.1097/00004583-200111000-00015

55. Ravens-Sieberer U. The Kidscreen Questionnaires: Quality Of Life Questionnaires For Children And Adolescents - Handbook. Lengerich: Pabst Science Publishers (2006).

56. Erhart M, Ottova V, Gaspar T, Jericek H, Schnohr C, Alikasifoglu M, et al. Measuring mental health and well-being of school-children in 15 European countries using the KIDSCREEN-10 Index. Int J Public Health. (2009) 54:1606. doi: 10.1007/s00038-009-5407-7

57. Ravens-Sieberer U, Erhart M, Rajmil L, Herdman M, Auquier P, Bruil J, et al. Reliability, construct and criterion validity of the KIDSCREEN-10 score: a short measure for children and adolescents' well-being and health-related quality of life. Qual Life Res. (2010) 19:1487-500. doi: 10.1007/s11136-010-9706-5

58. Preacher KJ, Hayes AF, SPSS and SAS procedures for estimating indirect effects in simple mediation models. Behav Res Methods Instrum Compu. (2004) 36:717-31. doi: 10.3758/BF03206553

59. Preacher KJ, Hayes AF. Asymptotic and resampling strategies for assessing and comparing indirect effects in multiple mediator models. Behav Res Methods. (2008) 40:879-91. doi: 10.3758/BRM.40.3.879

60. Hayes AF. Introduction to Mediation, Moderation, and Conditional Process Analysis: A Regression-Based Approach. New York, NY: Guilford publications (2017).

61. Baron RM, Kenny DA. The moderator-mediator variable distinction in social psychological research: conceptual, strategic, and statistical considerations. $J$ Pers Soc Psychol. (1986) 51:1173-82. doi: 10.1037/0022-3514.51.6.1173

62. Hayes AF. Beyond baron and kenny: statistical mediation analysis in the new millennium. Commun Monogr. (2009) 76:408-20. doi: 10.1080/03637750903310360

63. Gray HL, Buro AW, Ikan JB, Wang W, Stern M. School-level factors associated with obesity: a systematic review of longitudinal studies. Obes Rev. (2019) 20:1016-32. doi: 10.1111/obr.12852

64. Vik FN, Te Velde SJ, Van Lippevelde W, Manios Y, Kovacs E, Jan $\mathrm{N}$, et al. Regular family breakfast was associated with children's overweight and parental education: Results from the ENERGY crosssectional study. Prev Med. (2016) 91:197-203. doi: 10.1016/j.ypmed.2016. 08.013 
65. van Ansem WJC, van Lenthe FJ, Schrijvers CTM, Rodenburg G, van de Mheen D. Socio-economic inequalities in children's snack consumption and sugarsweetened beverage consumption: the contribution of home environmental factors. Br J Nutr. (2014) 112:467-76. doi: 10.1017/S0007114514001007

66. Kristiansen H, Júlíusson PB, Eide GE, Roelants M, Bjerknes R. TV viewing and obesity among Norwegian children: the importance of parental education. Acta Paediatr. (2013) 102:199-205. doi: 10.1111/apa.12066

67. Reiss F. Socioeconomic inequalities and mental health problems in children and adolescents: a systematic review. Soc Sci Med. (2013) 90:2431. doi: 10.1016/j.socscimed.2013.04.026

68. Gustafson SL, Rhodes RE. Parental correlates of physical activity in children and early adolescents. Sports Med. (2006) 36:79-97. doi: 10.2165/00007256-200636010-00006

69. von Rueden U, Gosch A, Rajmil L, Bisegger C, Ravens-Sieberer U. Socioeconomic determinants of health related quality of life in childhood and adolescence: results from a European study. J Epidemiol Community Health. (2006) 60:130-5. doi: 10.1136/jech.2005.039792

70. Blondin SA, Anzman-Frasca S, Djang HC, Economos CD. Breakfast consumption and adiposity among children and adolescents: an updated review of the literature. Pediatr Obes. (2016) 11:333-48. doi: 10.1111/ijpo.12082

71. Boone JE, Gordon-Larsen P, Adair LS, Popkin BM. Screen time and physical activity during adolescence: longitudinal effects on obesity in young adulthood. Int J Behav Nutr Phys Act. (2007) 4:26. doi: 10.1186/1479-5868-4-26

72. Forshee RA, Anderson PA, Storey ML. Sugar-sweetened beverages and body mass index in children and adolescents: a meta-analysis. Am J Clin Nutr. (2008) 87:1662-71. doi: 10.1093/ajcn/87.6.1662

73. Laverty AA, Magee L, Monteiro CA, Saxena S, Millett C. Sugar and artificially sweetened beverage consumption and adiposity changes: National longitudinal study. Int J Behav Nutr Phys Act. (2015) 12:137. doi: 10.1186/s12966-015-0297-y

74. Millar L, Rowland B, Nichols M, Swinburn B, Bennett C, Skouteris H, et al. Relationship between raised BMI and sugar sweetened beverage and high fat food consumption among children. Obesity. (2014) 22:E96103. doi: $10.1002 /$ oby. 20665

75. Sigmund E, El Ansari W, Sigmundová D. Does school-based physical activity decrease overweight and obesity in children aged 6-9 years? a two-year nonrandomized longitudinal intervention study in the Czech Republic. BMC Public Health. (2012) 12:570. doi: 10.1186/1471-2458-12-570

76. Jiménez-Pavón D, Kelly J, Reilly JJ. Associations between objectively measured habitual physical activity and adiposity in children and adolescents: Systematic review. Int J Pediatr Obes. (2010) 5:3-18. doi: 10.3109/17477160903067601

77. Devís-Devís J, Lizandra J, Valencia-Peris A, Pérez-Gimeno E, García-Massò X, Peiró-Velert C. Longitudinal changes in physical activity, sedentary behavior and body mass index in adolescence: migrations towards different weight cluster. PLoS ONE. (2017) 12:e0179502. doi: 10.1371/journal.pone.0179502

78. Hestetun I, Svendsen MV, Oellingrath IM. Associations between overweight, peer problems, and mental health in 12-13-year-old Norwegian children. Eur Child Adolesc Psychiatry. (2015) 24:319-26. doi: 10.1007/s00787-014-0581-4

79. Helseth S, Haraldstad K, Christophersen K-A. A cross-sectional study of health related quality of life and body mass index in a Norwegian school sample (8-18 years): a comparison of child and parent perspectives. Health Qual Life Outcomes. (2015) 13:47. doi: 10.1186/s12955-015-0239-z

80. Kolodziejczyk JK, Gutzmer K, Wright SM, Arredondo EM, Hill L, Patrick $\mathrm{K}$, et al. Influence of specific individual and environmental variables on the relationship between body mass index and health-related quality of life in overweight and obese adolescents. Qual Life Res. (2015) 24:25161. doi: 10.1007/s11136-014-0745-1

81. Ul-Haq Z, Mackay DF, Fenwick E, Pell JP. Meta-analysis of the association between body mass index and health-related quality of life among children and adolescents, assessed using the pediatric quality of life inventory index. $J$ Pediatr. (2013) 162:280-6. doi: 10.1016/j.jpeds.2012.07.049

82. Mech P, Hooley M, Skouteris H, Williams J. Parent-related mechanisms underlying the social gradient of childhood overweight and obesity: a systematic review: Understanding the social gradient of childhood obesity. Child Care Health Dev. (2016) 42:603-24. doi: 10.1111/cch.12356

83. Lynch J, Kaplan G. Socioeconomic Position. Social epidemiology. New York, NY: Oxford University Press (2000).

84. Lissau I, Sørensen TIA. Parental neglect during childhood and increased risk of obesity in young adulthood. Lancet. (1994) 343:324-7. doi: 10.1016/S0140-6736(94)91163-0

85. Papoutsou S, Savva SC, Hunsberger M, Jilani H, Michels N, Ahrens W, et al. Timing of solid food introduction and association with later childhood overweight and obesity: the IDEFICS study. Matern Child Nutr. (2018) 14:e12471. doi: $10.1111 / \mathrm{mcn} .12471$

86. Elsenburg LK, van Wijk KJ, Liefbroer AC, Smidt N. Accumulation of adverse childhood events and overweight in children: a systematic review and metaanalysis. Obesity. (2017) 25:820-32. doi: 10.1002/oby.21797

87. Barcellos SH, Carvalho LS, Turley P. Education can reduce health differences related to genetic risk of obesity. Proc Natl Acad Sci USA. (2018) 115:E976572. doi: 10.1073/pnas.1802909115

88. Gebremariam MK, Arah OA, Bergh IH, Andersen LF, Ommundsen Y, Totland $\mathrm{TH}$, et al. Gender-specific mediators of the association between parental education and adiposity among adolescents: the HEIA study. Sci Rep. (2019) 9:7282. doi: 10.1038/s41598-019-43604-w

89. Dollman J, Ridley K, Magarey A, Martin M, Hemphill E. Dietary intake, physical activity and TV viewing as mediators of the association of socioeconomic status with body composition: a cross-sectional analysis of Australian youth. Int J Obes. (2007) 31:45-52. doi: 10.1038/sj.ijo.0803524

90. Parikka S, Mäki P, Levälahti E, Lehtinen-Jacks S, Martelin T, Laatikainen T. Associations between parental BMI, socioeconomic factors, family structure and overweight in Finnish children: a path model approach. BMC Public Health. (2015) 15:271. doi: 10.1186/s12889-015-1548-1

91. Gosse MA. How accurate is self-reported BMI? Nutr Bull. (2014) 39:10514. doi: $10.1111 / \mathrm{nbu} .12075$

92. Frankenfield DC, Rowe WA, Cooney RN, Smith JS, Becker D. Limits of body mass index to detect obesity and predict body composition. Nutrition. (2001) 17:26-30. doi: 10.1016/S0899-9007(00)00471-8

93. Heinrichs N, Bertram H, Kuschel A, Hahlweg K. Parent recruitment and retention in a universal prevention program for child behavior and emotional problems: barriers to research and program participation. Prev Sci. (2005) 6:275-86. doi: 10.1007/s11121-005-0006-1

94. Warschburger P, Richter M. Prävention kindlichen Übergewichts: Elterliche Selbstwirksamkeit und Handlungsergebniserwartungen [Prevention of childhood obesity: Parental self-efficacy and outcome expectancy]. Zeitschrift für Gesundheitspsychologie. (2009) 17:22-9. doi: 10.1026/0943-8149.17.1.22

95. Plachta-Danielzik S, Landsberg B, Lange D, Langnäse K, Müller MJ. 15 years of the Kiel Obesity Prevention Study (KOPS). Results and its importance for obesity prevention in children and adolescents. Bundesgesundheitsbl Gesundheitsforschung Gesundheitsschutz. (2011) 54:30412. doi: 10.1007/s00103-010-1229-2

Conflict of Interest: The authors declare that the research was conducted in the absence of any commercial or financial relationships that could be construed as a potential conflict of interest.

Publisher's Note: All claims expressed in this article are solely those of the authors and do not necessarily represent those of their affiliated organizations, or those of the publisher, the editors and the reviewers. Any product that may be evaluated in this article, or claim that may be made by its manufacturer, is not guaranteed or endorsed by the publisher.

Copyright (C) 2022 Seum, Meyrose, Rabel, Schienkiewitz and Ravens-Sieberer. This is an open-access article distributed under the terms of the Creative Commons Attribution License (CC BY). The use, distribution or reproduction in other forums is permitted, provided the original author(s) and the copyright owner(s) are credited and that the original publication in this journal is cited, in accordance with accepted academic practice. No use, distribution or reproduction is permitted which does not comply with these terms. 